\title{
Developing a comprehensive measure of mobility: mobility over varied environments scale (MOVES)
}

\author{
Jana A. Hirsch ${ }^{1,2}$, Meghan Winters ${ }^{2,3^{*}}$ D, Joanie Sims-Gould ${ }^{2,4}$, Philippa J. Clarke ${ }^{5,6}$, Nathalie Ste-Marie ${ }^{7}$
} Maureen Ashe $^{2,4}$ and Heather A. McKay ${ }^{2,4,8}$

\begin{abstract}
Background: While recent work emphasizes the multi-dimensionality of mobility, no current measure incorporates multiple domains of mobility. Using existing conceptual frameworks we identified four domains of mobility (physical, cognitive, social, transportation) to create a "Mobility Over Varied Environments Scale" (MOVES). We then assessed expected patterns of MOVES in the Canadian population.

Methods: An expert panel identified survey items within each MOVES domain from the Canadian Community Health Survey- Healthy Aging Cycle (2008-2009) for 28,555 (weighted population $n=12,805,067$ ) adults ( $\geq 45$ years). We refined MOVES using principal components analysis and Cronbach's alpha and weighted items so each domain was 10 points. Expected mobility trends, as assessed by average MOVES, were examined by sociodemographic and health factors, and by province, using Analysis of Variance (ANOVA).

Results: MOVES ranged from 0 to 40, where 0 represents individuals who are immobile and 40 those who are fully mobile. Mean MOVES was 29.58 (95\% confidence interval (CI) 29.49, 29.67) (10th percentile: 24.17 (95\% Cl 23.96, 24. 38), 90th percentile: 34.70 (Cl 34.55, 34.85)). MOVES scores were lower for older, female, and non-white Canadians with worse health and lower socioeconomic status. MOVES was also lower for those who live in less urban areas.

Conclusions: MOVES is a holistic measure of mobility for characterizing older adult mobility across populations. Future work should examine individual or neighborhood predictors of MOVES and its relationship to broader health outcomes. MOVES holds utility for research, surveillance, evaluation, and interventions around the broad factors influencing mobility in older adults.
\end{abstract}

Keywords: Mobility limitation, Measurement, Methods, Functionally-Impaired elderly, Aged, Elderly, Surveys and questionnaires, Social interaction, Transportation

\section{Background}

While the pace and pattern of population shifts differ across the world, the older population is increasing globally [1]. In North America the proportion of the population 65 years and older is expected to rise from $12.8 \%$ in 2008 to $20.8 \%$ in 2040 [1]. This unprecedented shift demands that systems and communities meet needs of

\footnotetext{
* Correspondence: mwinters@sfu.ca

${ }^{2}$ Centre for Hip Health and Mobility, Robert H.N. Ho Research Centre, University of British Columbia, 5th Floor, 2635 Laurel St, Vancouver, BC, Canada

${ }^{3}$ Faculty of Health Sciences, Simon Fraser University, 8888 University Drive, Burnaby, BC, Canada

Full list of author information is available at the end of the article
}

this aging demographic. Mobility restrictions influence older adult independence [2], constrict community engagement $[3,4]$, and increase negative health outcomes and premature mortality $[5,6]$. Thus it is imperative that we devote collective attention to strategies and tools that support maintaining mobility later in life.

Mobility is multi-dimensional and includes the importance of social and community engagement, use of transportation, and cognition $[7,8]$. The Canadian Institute for Health Research (CIHR) acknowledged this broader definition of mobility; in the Mobility in Aging Strategic Initiative (CIHR Institute of Aging) mobility was defined as encompassing participation in society, as well as the 
ability to drive and access public transportation [9]. In the transportation realm, mobility is often measured as trip rate (any mode). In addition, transportation studies recognized that mobility should include one of the following dimensions: 1 ) access to places of desire (such as visiting family or friends), 2) psychological benefits of travel (either social contact or independence), or 3) benefits of physical movement itself and potential travel [10-12]. Urban planning recognized community environments as important in shaping mobility [13-20]. Understandably, advocacy groups focused on the role neighborhoods play in maintaining independence and mobility for older adults [21, 22].

Methods used to assess mobility vary across research studies and fields [7]. However, existing metrics often focus on an individual's capacity for, or enacted physical function. Cognitive ability to engage, social connections with an older person's community, or transportation choices are most often excluded from these metrics. Current measures of mobility include assessments of transfer skills, gait, or wheelchair mobility [23-25]. Activities of daily living (ADL) and instrumental activities of daily living (IADL) are also used to assess mobility clinically $[26,27]$. These methods were criticized as failing to capture what people actually do in their daily lives [28] or how an individual is involved in social situations [29]. Life-space measures attempt to capture broader mobility, by including mobility inside the home, outside the home, within the neighborhood, and beyond [28]. Yet the life-space measure does not capture transportation patterns or community engagement of older adults directly. Given the expanding definition of mobility, and the importance of mobility for older adults, there is a need for measures of mobility that encompass these domains. Therefore, we respond to both the opportunity and need for a holistic measure of older adult mobility that includes physical, cognitive, social, and transportation domains.

Thus the objectives of our study were twofold: 1) to create a Mobility Over Varied Environments Scale (MOVES) using a large, population based study of Canadian older adults, and 2) to apply MOVES to examine the distribution of mobility across sociodemographic and health characteristics of the Canadian population. This second objective allows us to examine the performance of MOVES. For this, we hypothesize that MOVES will follow known patterns of mobility, including lower mobility for Canadians in worse health, at older ages, or with lower socioeconomic status.

\section{Conceptual frameworks}

MOVES draws on the comprehensive mobility framework outlined by Webber et al. [7] and the World Health Organization's International Classification of
Functioning, Disability, and Health (ICF) [8]. Webber et al. defined mobility broadly as "the ability to move oneself (e.g., by walking, by using assistive devices, or by using transportation) within community environments that expand from one's home, to the neighborhood, and to regions beyond." This framework acknowledges that mobility takes many forms, including walking, using a wheelchair, driving, and using alternate forms of transportation. The Webber framework identifies five key domains that determine older adult mobility: physical, cognitive, psychosocial, environmental, and financial [7]. These domains are interrelated. For example, an individual's physical impairments (physical) with or without accompanying psychological factors (e.g. depression) can contribute to the development of fear of falling (cognitive), leading to activity restriction and reduced social engagement (psychosocial). Similarly, the ICF has a broad description of mobility that captures both indoor and outdoor movement as well as the use of assistive devices and transportation. Further, the description includes participation in activities and environmental factors that play a role in mobility.

\section{Methods MOVES creation}

We created MOVES based on the two conceptual frameworks outlined above. Its design was executed in an iterative process involving qualitative and quantitative researchers across multiple fields (Figure 1). The process had two broad steps: 1) concept-based creation of MOVES; and 2) statistical refinement, scoring and final compilation.

\section{Concept-based MOVES creation}

An expert panel of researchers and staff $(n=10)$ from gerontology, epidemiology, family medicine, transportation, and health behavior played a critical role in item selection. First, they helped synthesize existing mobility frameworks. Second, after two researchers separately identified items from the Canadian Community Health Survey- Healthy Aging (CCHS-HA) that related to the mobility frameworks, the expert panel determined which items to include.

\section{Statistical refinement}

On the selected items, we ran Cronbach's alpha and a confirmatory Principal Component Analysis (PCA) to determine whether: 1 ) items were contributing to their respective domains and the overall score, 2) the items grouped together as anticipated, and 3) what proportion of variance was explained by these items. Items were the combined into a final MOVES. 


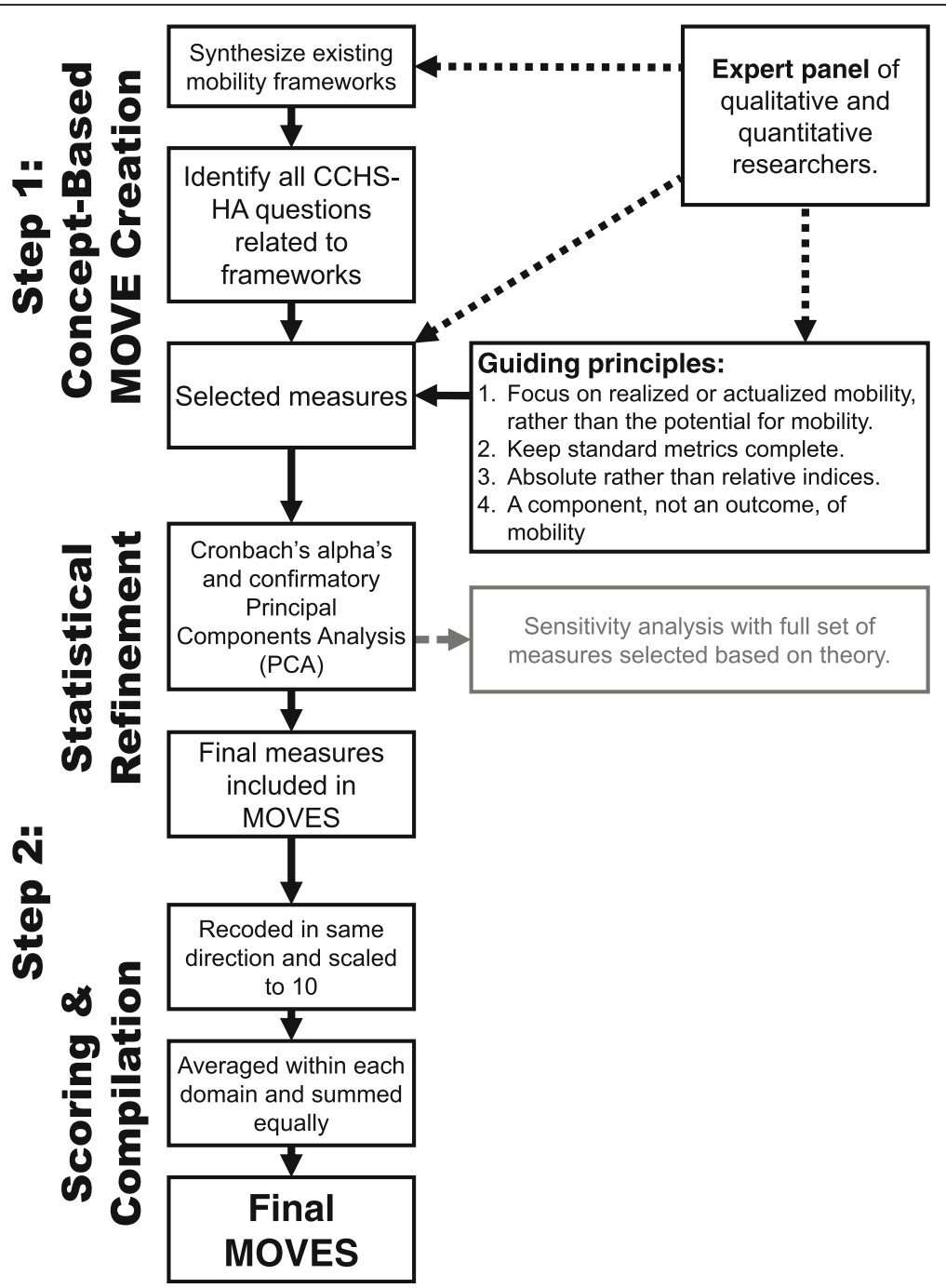

Fig. 1 Iterative process to create the Mobility Over Varied Environment Scale (MOVES). Dotted lines indicate the involvement of an expert panel of qualitative and quantitative researchers who played three key roles: 1) helping to synthesize the mobility frameworks 2) selecting specific items based on questions identified in CCHS-HA and 3) establishing guiding principles for the creation of MOVES that were used to select specific items in CCHS-HA. Note that the creation of MOVES was primarily based in conceptual frameworks and then underwent statistical refinement to both confirm frameworks and tailor the MOVES measure. A sensitivity analysis was run including all items based on frameworks (had barriers and limitations within each domain as well as an additional financial domain)

\section{Understanding canadian mobility using MOVES}

We applied MOVES to the CCHS-HA to better understand the distribution of mobility in the Canadian population. The CCHS-HA is a cross-sectional survey ( $n=30,865)$ of the Canadian population living in the 10 provinces across Canada (Canadian territories were excluded). Details can be found elsewhere [30]. Briefly the Healthy Aging component was completed December 2008 through November 2009 and surveyed people ( $\geq 45$ years) using computer assisted personal interviewing (94\% of interviews conducted in person) achieving an overall response rate of $74.4 \%$. For the creation of MOVES, we included CCHS-HA participants who had all component items that comprised MOVES (final $n=28,555$ ).
Weighted frequencies were used to describe the sociodemographic characteristics of the CCHS-HA sample. MOVES mean score was examined across each sociodemographic characteristic. We obtained $p$ values for comparisons across categories from t-tests and analysis of variance (ANOVA). MOVES mean score was also compared across age and gender within each province. We weighted all results using the Statistics Canada proportional sampling scheme and applied Balanced Repeated Replication (BRR) with 500 bootstrap weight variables to obtain the correct standard errors for ANOVA. All analyses were conducted using SAS, version 9.4 (SAS Institute Incorporated: Cary, NC). 


\section{Results- moves creation}

\section{Item selection}

To select items, the expert panel established four guiding principles: 1) MOVES should focus on actualized or realized mobility of an individual, rather than potential for mobility (e.g. how often one engages in community activities versus whether community activities exist), 2) if there were existing metrics within a domain, these metrics should remain intact, rather than being split into their component parts, 3) where possible, MOVES should be an absolute rather than a relative metric, to be applicable beyond the Canadian population, and 4) items should represent components, rather than outcomes, of mobility (e.g. loneliness was excluded as it may result from low social engagement).

\section{MOVES domains}

In practice, the measurement of Webber's psychosocial domain and cognitive domain overlap. Therefore, to develop MOVES we modified the psychosocial domain to be primarily social, based on the complementary domain from the ICF, "activities and participation." This domain includes interpersonal interactions and relationships, as well as community social and civic life. Similarly, many of the environmental determinants in both Webber and ICF models are related to service systems and policies that influence transportation mode. Therefore, this domain was conceptualized more narrowly in our work as "transportation."

\section{Physical}

Our expert panel identified eight items (five of which were barriers or limitations) to include in the physical domain (Table 1). We used activities of daily living (ADL), ambulation, and physical activity items to capture physical function and activity. ADL items excluding meal preparation come from the Older Americans Resources and Services (OARS) Multidimensional Functional Assessment Questionnaire $\odot$ (OMFAQ) [31]. Ambulation items were from the adapted version of the Health Utilities Index (HUI) mark 3 [32], a validated instrument which provides a description of an individual's overall functional health. Because sedentary behavior and physical activity independently predict successful aging [33], physical activity was measured using the Physical Activity Scale for the Elderly (PASE), a validated and copyrighted instrument (1991) developed by the New England Research Institutes (NERI) to provide an overall assessment of self-reported occupational, household and leisure activities over the past seven days in older persons [34]. Barriers and limitations included reporting a health condition limiting participation in activities, public transportation use, or health improvements.

\section{Cognitive}

In the psychological and cognitive domain, we used two items, one for cognition and one that measured fear of falling. Cognition was captured with the HUI cognitive health status [32]. This measures whether a respondent can remember most things, think clearly, and solve dayto-day problems. We used fear of falling to tap into selfefficacy around mobility. A survey item related to fear of falling was administered to all those 65 years or older (response categories: not worried or concerned, worried or concerned but haven't stopped activities, and worried or concerned and have stopped activities).

\section{Transportation}

Transportation was measured using four items, one represented travel mode of the respondent and three reported transportation-related barriers and limitations. For travel mode, participants answered the question, "in the past month, which of the following (other) forms of transportation have you used?" Respondents were given the options: passenger in a motor vehicle; taxi; public transportation such as bus, rapid transit, subway or train, accessible transit, cycling, walking, wheelchair or motorized cart, or none. Barriers and limitation included reporting transportation problems that limited their participation or ability to improve their health.

\section{Social}

Social aspects of mobility were measured using three items: a sense of belonging to the local community; frequency of participation in community activities; and tangible social support. Sense of belonging was measured by asking respondents "How would you describe your sense of belonging to your local community? Frequency of community-related activity participation was assessed by participation in any type of community-related activity during the previous 12 months and then categorized as participation once a year, once a month, once a week, or once a day. Tangible social support was taken from the Medical Outcomes Study (MOS) Social Support Survey [35]. This scale ranges from 0 to 16 and was not asked during proxy interviews; therefore proxy respondents do not have a MOVES score.

\section{Financial}

The expert panel identified that an individual's financial standing influences and interacts with the other domains. However, since income or wealth are not actualized mobility, we only included financial markers of whether an individual felt cost prohibited them from being mobile or engaging with their community (barriers and limitations). Ultimately, this domain was not included in MOVES due to findings during the statistical refinement process described below. 
Table 1 Full set of component items for each domain of the MOVES included in both the final MOVES score and sensitivity analysis

\begin{tabular}{|c|c|c|}
\hline Item & Points toward MOVES ${ }^{a}$ & $\begin{array}{l}\text { Weighted Percer } \\
\text { responses }(95 \%\end{array}$ \\
\hline \multicolumn{3}{|l|}{ Physical Domain } \\
\hline \multicolumn{3}{|l|}{ Instrumental \& Basic Activities of Daily Living Classification } \\
\hline No Functional Impairment & 10 & $89.1(88.5,89.6)$ \\
\hline Mild Impairment & 7.5 & $7.9(7.4,8.4)$ \\
\hline Moderate Impairment & 5 & $2.1(1.8,2.3)$ \\
\hline Severe Impairment & 2.5 & $0.5(0.4,0.6)$ \\
\hline Total Impairment & 0 & $0.5(0.4,0.6)$ \\
\hline \multicolumn{3}{|l|}{ Ambulation (Mobility) } \\
\hline $\begin{array}{l}\text { Able to walk around the neighbourhood without difficulty, } \\
\text { and without walking equipment }\end{array}$ & 10 & $93.4(93.0,93.8)$ \\
\hline $\begin{array}{l}\text { Able to walk around the neighbourhood with difficulty; } \\
\text { but does not require walking equipment or the help of another person }\end{array}$ & 8 & $1.2(1.0,1.4)$ \\
\hline $\begin{array}{l}\text { Able to walk around the neighbourhood with walking equipment, } \\
\text { but without the help of another person }\end{array}$ & 6 & $3.7(3.4,4.0)$ \\
\hline $\begin{array}{l}\text { Able to walk only short distances with walking equipment, } \\
\text { and requires a wheelchair to get around the neighbourhood }\end{array}$ & 4 & $0.3(0.2,0.3)$ \\
\hline $\begin{array}{l}\text { Unable to walk alone, even with walking equipment. Able to walk } \\
\text { short distances with the help of another person, and requires a } \\
\text { wheelchair to get around the neighbourhood }\end{array}$ & 2 & $1.1(0.9,1.2)$ \\
\hline Cannot walk at all & 0 & $0.3(0.3,0.4)$ \\
\hline \multicolumn{3}{|l|}{ Physical Activity Scale for the Elderly (PASE) Score } \\
\hline Quartile 1 & 10 & $25.1(24.0,26.1)$ \\
\hline Quartile 2 & 6.67 & $25.1(24.1,26.1)$ \\
\hline Quartile 3 & 3.33 & $25.1(24.1,26.0)$ \\
\hline Quartile 4 & 0 & $24.8(23.9,25.7)$ \\
\hline Reported that health condition limited participation in (more) activities ${ }^{b}$ & -1 & $5.8(5.4,6.2)$ \\
\hline Reported that health condition limited use of public transportation ${ }^{b}$ & -1 & $2.0(1.8,2.2)$ \\
\hline Reported that health condition limited use of accessible transportation ${ }^{\text {b }}$ & -1 & $0.5(0.4,0.5)$ \\
\hline Reported that physical condition is a barrier to improve health ${ }^{\mathrm{b}}$ & -1 & $2.8(2.5,3.1)$ \\
\hline Reported that disability or health problem is a barrier to improve ${ }^{b}$ & -1 & $3.6(3.3,4.0)$ \\
\hline \multicolumn{3}{|l|}{ Cognitive Domain } \\
\hline \multicolumn{3}{|l|}{ Cognition } \\
\hline Able to remember most things, think clearly and solve day to day problems & 10 & $73.9(73.0,74.9)$ \\
\hline $\begin{array}{l}\text { Able to remember most things, but have a little difficulty when trying to think } \\
\text { and solve day to day problems }\end{array}$ & 8 & $2.2(1.9,2.5)$ \\
\hline Somewhat forgetful, but able to think clearly and solve day to day problems & 6 & $17.2(16.3,18.0)$ \\
\hline $\begin{array}{l}\text { Somewhat forgetful, and have a little difficulty when trying to think or solve } \\
\text { day to day problems }\end{array}$ & 4 & $5.0(4.6,5.5)$ \\
\hline $\begin{array}{l}\text { Very forgetful, and have great difficulty when trying to think or solve day to } \\
\text { day problems }\end{array}$ & 2 & $1.4(1.2,1.6)$ \\
\hline $\begin{array}{l}\text { Unable to remember anything at all, and unable to think or solve } \\
\text { day to day problems }\end{array}$ & 0 & $0.2(0.1,0.3)$ \\
\hline \multicolumn{3}{|l|}{ Fear of falling } \\
\hline Not applicable ( $<65$ years old $)$ & 10 & $68.1(67.2,68.9)$ \\
\hline Not worried or concerned about future falls & 10 & $21.2(20.5,21.9)$ \\
\hline Worried or concerned about future falls, have not stopped activities & 5 & $6.0(5.6,6.3)$ \\
\hline Worried or concerned about future falls, have stopped some activities & 0 & $4.8(4.5,5.0)$ \\
\hline
\end{tabular}


Table 1 Full set of component items for each domain of the MOVES included in both the final MOVES score and sensitivity analysis (Continued)

Transport Domain

Number of modes (comprised of the modes below)

No Modes

1 Mode

2 Modes

3 Modes

4 Modes

Modes of transport used in past month ${ }^{c}$

Drive (at least once in past week)

Passenger (passenger/taxi)

Transit (public transit/accessible transit)

Active travel (cycling/walking)

Reported that transportation problems limited participation in (more) activities ${ }^{\mathrm{b}}$

Reported that transportation problems is a barrier to improve health ${ }^{\text {b }}$

Reported that transportation problems are the reason they did not see the dentist ${ }^{b}$

Social Domain

Sense of belonging to local community

Very strong

Somewhat strong

Somewhat weak

Very weak

Frequency of participation in a community-related activity

Did not participate in a community-related activity

Participated at least once a year

Participated at least once a month

Participated at least once a week

Participated at least once a day

Tangible social support (higher values indicate higher social support)

Index score from 0 to 16

$$
0
$$

0.625

1.25

1.875

2.5

3.125

3.75

4.375

5

5.625

6.25

6.875

7.5

8.125
$0.3(0.2,0.4)$

$30.2(29.2,31.2)$

36.7 (35.6, 37.8)

$25.4(24.4,26.3)$

$7.5(6.8,8.1)$

$83.0(82.3,83.7)$

$64.5(63.4,65.6)$

$21.9(21.0,22.9)$

$40.2(39.1,41.3)$

$1.3(1.1,1.5)$

$0.2(0.1,0.3)$

$0.0(0.0,0.1)$

$22.1(21.2,23.0)$

$44.0(42.8,45.1)$

$23.4(22.5,24.4)$

$10.1(9.5,10.8)$

$1.9(1.7,2.1)$

$4.5(4.0,4.9)$

$20.8(19.8,21.7)$

$60.9(59.8,62.0)$

$11.9(11.2,12.7)$

$0.8(0.6,1.0)$

$0.4(0.3,0.6)$

$0.6(0.4,0.7)$

$0.7(0.6,0.9)$

$1.2(0.9,1.4)$

$1.0(0.8,1.1)$

$1.4(1.1,1.6)$

$1.7(1.4,1.9)$

$3.1(2.7,3.4)$

$2.6(2.3,2.9)$

$3.8(3.4,4.2)$

$4.3(3.9,4.7)$

$10.9(10.1,11.7)$

$6.4(5.9,7.0)$ 
Table 1 Full set of component items for each domain of the MOVES included in both the final MOVES score and sensitivity analysis (Continued)

\begin{tabular}{llc}
\hline 14 & 8.75 & $8.3(7.7,9.0)$ \\
15 & 9.375 & $9.9(9.2,10.6)$ \\
16 & 10 & $43.0(41.8,44.1)$ \\
Financial Domain $^{d}$ & -1 & $3.2(2.8,3.6)$ \\
Reported that cost limited participation in (more) activities $^{\text {b }}$ & -1 & $0.6(0.4,0.8)$ \\
Reported that cost limited use of public transportation $^{\text {b }}$ & -1 & $0.3(0.2,0.5)$ \\
Reported that cost limited use of accessible transportation $^{\text {b }}$ & -1 & $1.5(1.3,1.7)$ \\
Reported that cost is a barrier to improve health $^{\text {b }}$ & & \\
\hline a All compont
\end{tabular}

${ }^{a}$ All component items coded so that higher points indicate more positive mobility and then scaled to be between 0 and 10 points. Barriers each coded as penalties of 1 point

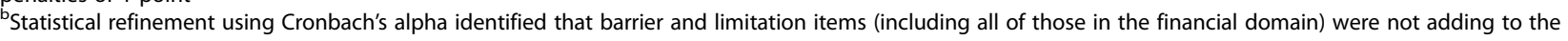
overall MOVES or the domains. These items only used in sensitivity analyses

${ }^{\mathrm{C}}$ Number of modes was used for the MOVES, but the breakdown of each transport mode is also presented for descriptive purposes

${ }^{\mathrm{d}}$ The Financial Domain was not included in the final MOVES due to results of the statistical refinement

\section{Statistical refinement, scoring and compilation}

We ran Cronbach's alpha to determine internal consistency for all items (0.61) and within each domain (range from 0.11-0.64). By examining Cronbach's alpha if each item were deleted, we identified that MOVES performed equally well without barrier and limitation items (including all those in the financial domain). After removing these items, the final MOVES standardized Cronbach's alpha was 0.58. The cognitive domain had the lowest internal consistency, likely because cognitive function and fear of falling tap into different, yet related, elements of mobility-related cognition or psychology.

We ran PCA both on all items identified by the expert panel and just on items remaining after Cronbach's alpha analysis. We ran these PCA with no restrictions placed on number of factors as well as with factor constraints equal to the number of domains. In general, items grouped within the anticipated domains. However, fear of falling loaded onto both the cognitive and physical domain and transportation mode loaded onto a number of factors. This cross-over between factors was expected, as theoretical frameworks include interconnectedness between domains. PCA also confirmed we should restrict to only four domains; in the solution including all items, the first five factors accounted for only $39.1 \%$ of variance (all five had eigenvalues greater than 1). In the solution using only the subset of items indicated by Cronbach's alpha, the first four factors accounted for $62.3 \%$ of the variance (only the first three had eigenvalues greater than 1). Thus, statistical refinement using PCA confirmed that removing barriers and limitations (including the entire financial domain) from MOVES created an equally sound score.

We provide final items and scoring for items in MOVES in Table 1. All items (except PASE) were categorical and were left in their original metrics based on the guiding principle for absolute versus relative items. Scores were recoded so higher values indicate greater mobility and then were scaled to 10 points. As recommended by Statistics Canada [30], PASE data were used as quartiles. Since respondents aged under 65 were not asked about their fear of falling, we allocated them 10 points. We chose to allocate points based on the number of transportation modes each respondent reported. We did not prioritize active mode, aligned with the conceptual frameworks that considered all forms of transportation as important to mobility. We grouped transportation modes as: driving oneself (having a driver's license and driving at least once in the previous month), being driven (being a passenger or taking a taxi), taking public or accessible transit (where accessible transit included service designed for persons with disabilities or mobility issues), and active transit (walking or cycling for transportation). Items within each domain were averaged, so each domain received an equal weight of 10 points. The final MOVES was created by summing across four domains for a possible score of 0 to 40 .

\section{Results \\ Canadian mobility CCHS sample}

In the weighted sample, $49 \%$ were female, most were between ages 45 and 64 (Table 2). A majority were married, white, Canadian, still working, have postsecondary education, own their homes, live in single detached houses, and live with their family. Most do not receive home care, were satisfied or extremely satisfied with life, have at least one chronic condition, drink regularly, do not have arthritis, have experienced no falls, and did not feel depressed or lose interest in things (Table 3 ). 
Table 2 Distribution of MOVES across sociodemographic and economic characteristics

\begin{tabular}{|c|c|c|c|}
\hline Sociodemographic or Economic Characteristics & Weighted Percentage (95\% Cl) & Mean MOVES (95\% Cl) & $p$-value for MOVES ${ }^{a}$ \\
\hline Sex & & & $<.0001$ \\
\hline Male & $44.9(43.7,46.0)$ & $29.9(29.8,30.0)$ & \\
\hline Female & $49.0(47.9,50.2)$ & $29.3(29.1,29.4)$ & \\
\hline Age & & & $<.0001$ \\
\hline $45-54$ & $36.7(35.4,37.9)$ & $30.8(30.6,30.9)$ & \\
\hline $55-64$ & $28.0(27.1,28.9)$ & $30.4(30.2,30.5)$ & \\
\hline $65-74$ & $16.6(16.0,17.2)$ & $28.5(28.3,28.6)$ & \\
\hline $75-84$ & $9.7(9.3,10.1)$ & $26.5(26.3,26.7)$ & \\
\hline $85+$ & $3.0(2.8,3.2)$ & $24.0(23.7,24.3)$ & \\
\hline Worked at job or business & & & $<.0001$ \\
\hline Yes & $57.3(56.2,58.3)$ & $31.0(30.8,31.1)$ & \\
\hline No & $38.8(37.8,39.8)$ & $27.6(27.4,27.7)$ & \\
\hline Retirement status & & & $<.0001$ \\
\hline Completely retired & $33.0(32.0,33.9)$ & $27.9(27.8,28.0)$ & \\
\hline Partially retired or not retired & $61.7(60.7,62.7)$ & $30.7(30.6,30.8)$ & \\
\hline Highest level of education & & & $<.0001$ \\
\hline Less than or secondary school graduation & $24.6(23.7,25.5)$ & $27.9(27.8,28.1)$ & \\
\hline Some post-secondary & $4.5(4.1,5.0)$ & $29.7(29.3,30.1)$ & \\
\hline Post-secondary graduation & $64.9(63.9,65.9)$ & $30.2(30.1,30.3)$ & \\
\hline Total household income from all sources & & & $<.0001$ \\
\hline Less than $\$ 19,999$ & $9.1(8.6,9.6)$ & $26.3(26.0,26.5)$ & \\
\hline$\$ 20,000$ TO $\$ 49,999$ & $28.3(27.3,29.3)$ & $28.5(28.4,28.6)$ & \\
\hline$\$ 50,000$ TO $\$ 99,999$ & $33.8(32.6,35.0)$ & $30.4(30.2,30.5)$ & \\
\hline$\$ 100,000$ and over & $24.1(22.9,25.2)$ & $31.5(31.3,31.7)$ & \\
\hline Region or Province of residence & & & $<.0001$ \\
\hline Atlantic & $7.2(6.9,7.5)$ & $29.1(28.9,29.2)$ & \\
\hline Quebec & $23.2(22.3,24.2)$ & $28.9(28.7,29.0)$ & \\
\hline Ontario & $36.4(35.2,37.6)$ & $29.6(29.4,29.7)$ & \\
\hline Prairies & $14.6(14.0,15.2)$ & $30.2(30.1,30.4)$ & \\
\hline British Columbia & $12.5(11.8,13.2)$ & $30.5(30.2,30.7)$ & \\
\hline Population size group & & & 0.0033 \\
\hline Rural area & $15.1(14.2,16.0)$ & $29.2(29.0,29.4)$ & \\
\hline Urban area $<100,000$ & $13.4(12.7,14.2)$ & $29.4(29.2,29.6)$ & \\
\hline$\geq 100,000$ to $<500,000$ & $21.2(20.3,22.0)$ & $29.5(29.4,29.7)$ & \\
\hline$\geq 500,000$ & $44.2(43.1,45.3)$ & $29.8(29.6,29.9)$ & \\
\hline Flag for tenure of dwelling & & & $<.0001$ \\
\hline Not owned by the respondent & $16.9(16.1,17.7)$ & $27.8(27.6,28.0)$ & \\
\hline Owned by the respondent & $77.5(76.6,78.4)$ & $30.0(29.9,30.1)$ & \\
\hline Type of dwelling & & & $<.0001$ \\
\hline Single detached house & $67.4(66.4,68.4)$ & $30.0(29.9,30.1)$ & \\
\hline Double, row or terrace, duplex house & $10.6(10.0,11.3)$ & $29.5(29.2,29.8)$ & \\
\hline Low-rise or high rise apartment & $14.2(13.6,14.9)$ & $27.9(27.7,28.1)$ & \\
\hline Mobile home or other & $1.6(1.4,1.8)$ & $28.6(28.2,29.1)$ & \\
\hline
\end{tabular}


Table 2 Distribution of MOVES across sociodemographic and economic characteristics (Continued)

\begin{tabular}{lll}
\hline Household size & & $27.8(27.7,28.0)$ \\
Alone & $17.5(16.9,18.2)$ & $29.6(29.5,29.7)$ \\
2 people & $45.3(44.2,46.4)$ & $30.5(30.4,30.7)$ \\
3 or more & $31.1(29.9,32.3)$ & \\
Marital status & & $30.1(30.0,30.2)$ \\
Married or common-law & $69.8(68.9,70.7)$ & $27.7(27.5,27.8)$ \\
Widowed, separated, or divorced & $18.3(17.7,19.0)$ & $28.8(28.5,29.2)$ \\
Single, or never married & $5.8(5.3,6.2)$ & $29.3(29.0,29.5)$ \\
Cultural/Racial Background & & $29.6(29.5,29.7)$ \\
Not White & $11.4(10.6,12.2)$ & \\
White & $83.0(82.1,83.9)$ & $29.3(29.1,29.5)$ \\
Immigrant & & $29.7(29.6,29.8)$ \\
Yes & $22.8(21.9,23.8)$ & 0.0251 \\
No & $71.6(70.6,72.6)$ & $29.7(29.6,29.8)$ \\
County of Birth & & $29.8(29.2,30.4)$ \\
Canada & $70.9(69.9,72.0)$ & $29.3(29.1,29.5)$ \\
Other North America & $1.1(0.9,1.3)$ & $<.0042$ \\
Others & $22.3(21.4,23.3)$ & $<.0001$ \\
\hline
\end{tabular}

ap-values from t-test or ANOVA testing for differences in mean MOVE. All results weighted using the Statistics Canada proportional sampling scheme and applied Balanced Repeated Replication (BRR) with 500 bootstrap weight variables to obtain the correct standard errors for ANOVA

\section{MOVES descriptive statistics}

Within the 28,555 adults with complete data to create MOVES, the 10th percentile of MOVES was 24.2 (95\% confidence interval (CI) 24.0, 24.4) and the 90th percentile was 34.7 (CI 34.6, 34.9), with a mean of 29.6 (CI 29.5, 29.7). Scores were generally high within each MOVES domain, although differences existed in each domain by age (Figure 2). Out of 10, Canadians scored a mean physical mobility of 8.1 (95\% CL 8.1, 8.1), mean cognitive mobility of 9.0 (95\% CL 9.0, 9.1), and mean social mobility of 7.1 (95\% CL 7.0, 7.1). Over $90 \%$ used between one and three transportation modes, giving a mean transportation mobility score of 5.2 (95\% CL 5.2, 5.3).

MOVES was higher for those who were younger, male, white, better educated, employed, higher income, married, home owners, born in Canada, and living in larger urban areas (Table 2). Higher MOVES was also associated with healthier behaviors and better health outcomes (Table 3). Those with excellent self-perceived health had an average MOVES of 31.2 (CI 31.0, 31.4), compared with those with poor self-perceived health, who had an average MOVES of 24.0 (CI 23.5, 24.4). Lower values for MOVES by age were statistically significantly different for males and females $(p<0.001)$ with females having a steeper decline in mobility across age groups (Figure 3 ).

MOVES varied across the provinces $(p<0.0001)$ and declines across age groups also varied by province/region ( $p=0.065$, Additional file 1: Fig. S1). Similarly, gender differences in mobility decline differed by province/region ( $p=0.070$, Additional file 2: Fig. S2a and Additional file 3: Fig. S2b).

\section{Discussion}

We used data from a large, population-based study to create a comprehensive measure of mobility, MOVES, that encompasses multiple domains of actualized mobility for mid- to late-life adults living in the community. Grounded in evidence and conceptual frameworks, and refined using input from experts and statistical analysis, MOVES captures the complexity inherent in mobility, including physical, cognitive, social, and transportation domains. Across the representative sample of Canadian older adults, MOVES aligns with expected mobility patterns (higher for those who were younger, higher socioeconomic status, and in better health).

The creation of a holistic mobility score bridges gaps between other classification systems, as it better captures where people go, what they do in their daily lives, and their social connections to others. In contrast to typical clinical measures that focus on physical capacity [6], MOVES provides researchers, practitioners, and policymakers the opportunity to evaluate actualized mobility more broadly. Particularly noteworthy is our inclusion of transport modes. Older adults out-of-home activity levels decrease with driving cessation [3], and cessation of driving was associated with worse health outcomes [36], although directionality of these associations is 
Table 3 Distribution of MOVES across healthcare utilization, health behaviours, or health outcomes

\begin{tabular}{|c|c|c|c|}
\hline Health Characteristics & Weighted Percentage (95\% Cl) & Mean MOVES (95\% Cl) & $p$-value for MOVES ${ }^{a}$ \\
\hline Receipt of Home Care & & & $<.0001$ \\
\hline Did not receive home care & $81.9(81.2,82.7)$ & $30.1(30.0,30.2)$ & \\
\hline Informal home care only & $1.8(1.6,2.0)$ & $26.9(26.6,27.2)$ & \\
\hline Formal home care only & $7.6(7.1,8.0)$ & $25.8(25.2,26.4)$ & \\
\hline Both formal and informal home care & $2.7(2.4,2.9)$ & $23.5(23.1,24.0)$ & \\
\hline Self-perceived health & & & $<.0001$ \\
\hline Excellent & $19.4(18.4,20.4)$ & $31.2(31.0,31.4)$ & \\
\hline Very good & $32.0(30.9,33.0)$ & $30.6(30.4,30.7)$ & \\
\hline Good & $28.3(27.4,29.3)$ & $29.1(29.0,29.3)$ & \\
\hline Fair & $10.8(10.2,11.4)$ & $26.7(26.5,27.0)$ & \\
\hline Poor & $3.5(3.1,3.8)$ & $24.0(23.5,24.4)$ & \\
\hline Satisfaction with Life Scale & & & $<.0001$ \\
\hline Extremely dissatisfied & $1.2(1.0,1.4)$ & $25.6(24.8,26.4)$ & \\
\hline Dissatisfied & $3.1(2.7,3.5)$ & $26.8(26.2,27.4)$ & \\
\hline Slightly dissatisfied & $6.2(5.6,6.7)$ & $27.4(27.0,27.8)$ & \\
\hline Neutral & $1.7(1.4,1.9)$ & $27.6(26.9,28.3)$ & \\
\hline Slightly satisfied & $13.2(12.5,14.0)$ & $28.6(28.4,28.8)$ & \\
\hline Satisfied & $47.3(46.2,48.5)$ & $29.9(29.8,30.0)$ & \\
\hline Extremely satisfied & $23.6(22.7,24.6)$ & $30.9(30.7,31.0)$ & \\
\hline Reported having a chronic condition & & & $<.0001$ \\
\hline Has at least one chronic condition & $73.1(72.0,74.2)$ & $29.2(29.1,29.3)$ & \\
\hline Has no chronic conditions & $21.0(19.9,22.0)$ & $30.9(30.8,31.1)$ & \\
\hline Smoking Status & & & $<.0001$ \\
\hline Smoker & $17.4(16.5,18.3)$ & $29.2(29.0,29.4)$ & \\
\hline Former smoker & $45.8(44.7,46.9)$ & $29.7(29.6,29.9)$ & \\
\hline Never smoked & $30.7(29.7,31.8)$ & $29.5(29.4,29.7)$ & \\
\hline Drinking Status & & & $<.0001$ \\
\hline Regular drinker & $58.0(56.9,59.1)$ & $30.3(30.2,30.4)$ & \\
\hline Occasional drinker & $16.3(15.5,17.2)$ & $29.2(28.9,29.4)$ & \\
\hline Did not drink in the last 12 months & $19.6(18.8,20.4)$ & $27.7(27.5,27.9)$ & \\
\hline Reported having arthritis & & & $<.0001$ \\
\hline Yes & $26.0(25.1,26.9)$ & $28.1(27.9,28.2)$ & \\
\hline No & $67.9(66.9,68.9)$ & $30.2(30.1,30.3)$ & \\
\hline Self-reported BMI & & & $<.0001$ \\
\hline Underweight (<18.50) & $1.4(1.2,1.5)$ & $27.1(26.4,27.7)$ & \\
\hline Normal weight (18.50-24.99) & $37.4(36.3,38.5)$ & $29.6(29.5,29.8)$ & \\
\hline Overweight (25.00-29.99) & $36.2(35.1,37.3)$ & $29.8(29.7,30.0)$ & \\
\hline Obese-class I, class 2, class 3 ( $\geq 30.00)$ & $21.2(20.3,22.2)$ & $29.4(29.2,29.6)$ & \\
\hline Number of falls (only 65+) & & & $<.0001$ \\
\hline No & $73.7(72.7,74.7)$ & $27.8(27.7,27.9)$ & \\
\hline One fall & $11.5(10.7,12.2)$ & $26.4(26.0,26.7)$ & \\
\hline Two or more falls & $6.3(5.8,6.8)$ & $24.2(23.7,24.7)$ & \\
\hline
\end{tabular}


Table 3 Distribution of MOVES across healthcare utilization, health behaviours, or health outcomes (Continued)

\begin{tabular}{lll}
\hline Depressive Symptoms & & $<.0001$ \\
Did not feel depressed or did not lose interest in things & $88.9(88.2,89.5)$ & $29.7(29.6,29.8)$ \\
Felt depressed or lost interest in things & $7.7(7.1,8.3)$ & $28.1(27.8,28.5)$ \\
\hline
\end{tabular}

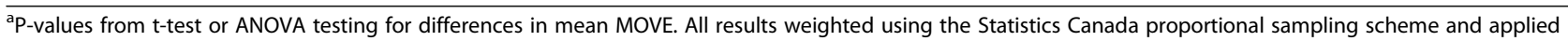
Balanced Repeated Replication (BRR) with 500 bootstrap weight variables to obtain the correct standard errors for ANOVA

unclear. Thus, including both automobile use and transportation alternatives was critical to characterizing older adult mobility. Another novel component of MOVES is its ability to capture social engagement and mobility through tangible social support, sense of belonging, and frequency of participation in community events. Links between social support, health, and overall mortality have been well documented [37, 38], giving further credence to the importance of including social connections and community participation in a mobility score.

The sociodemographic and economic patterns we observed in MOVES align with previous literature on older adult activity [39]. As expected, mobility declines with age. MOVES is higher for men, and declines over age were steeper for women than for men. This differential decline is consistent with reports of ADL in older women [40], and may be due to smaller support networks due to employment patterns, or potential differences in driving. However, gender differences could also result from survivor bias as studies of functional decline show men as less likely to survive [40], possibly resulting in a select group of stronger, more mobile males at older ages. Lower MOVES for those with lower income, education, employment, and home ownership, are consistent with evidence on the role of socioeconomic status in functional status [41], chronic disease [42], and mortality [43]. However, there remains controversy about the mechanisms linking socioeconomic status to mobility
[44]. Income and wealth may factor into neighborhood choices, providing fewer options for lower socioeconomic adults. Similarly, educational or occupational differences may afford disparate out of home engagement opportunities or access tools to cope with declines in physical functioning.

Interestingly, we observed higher levels of mobility for Canadians living in larger urban areas. This highlights the need for continued research to differentiate between needs of older adults in rural versus urban centres, and the need to address rural seniors' health needs $[45,46]$. Alternatively, larger-scale geographic patterns by region may be more useful as descriptive distributions of mobility for resource allocation and health care service provision (which is under provincial jurisdiction in Canada). Not surprising, we found those with higher MOVES had better health outcomes, including self-perceived health, life satisfaction, and fewer chronic conditions, normal body weight, fewer depressive symptoms, and fewer falls. These descriptive results are consistent with research findings that life space is associated with health and mortality $[5,47]$. Our paper investigated whether trends in our new mobility measure, MOVES, tracked with prevailing literature on mobility patterns. More in-depth analyses should explore the associations between sociodemographic and economic factors, MOVES and health outcomes.

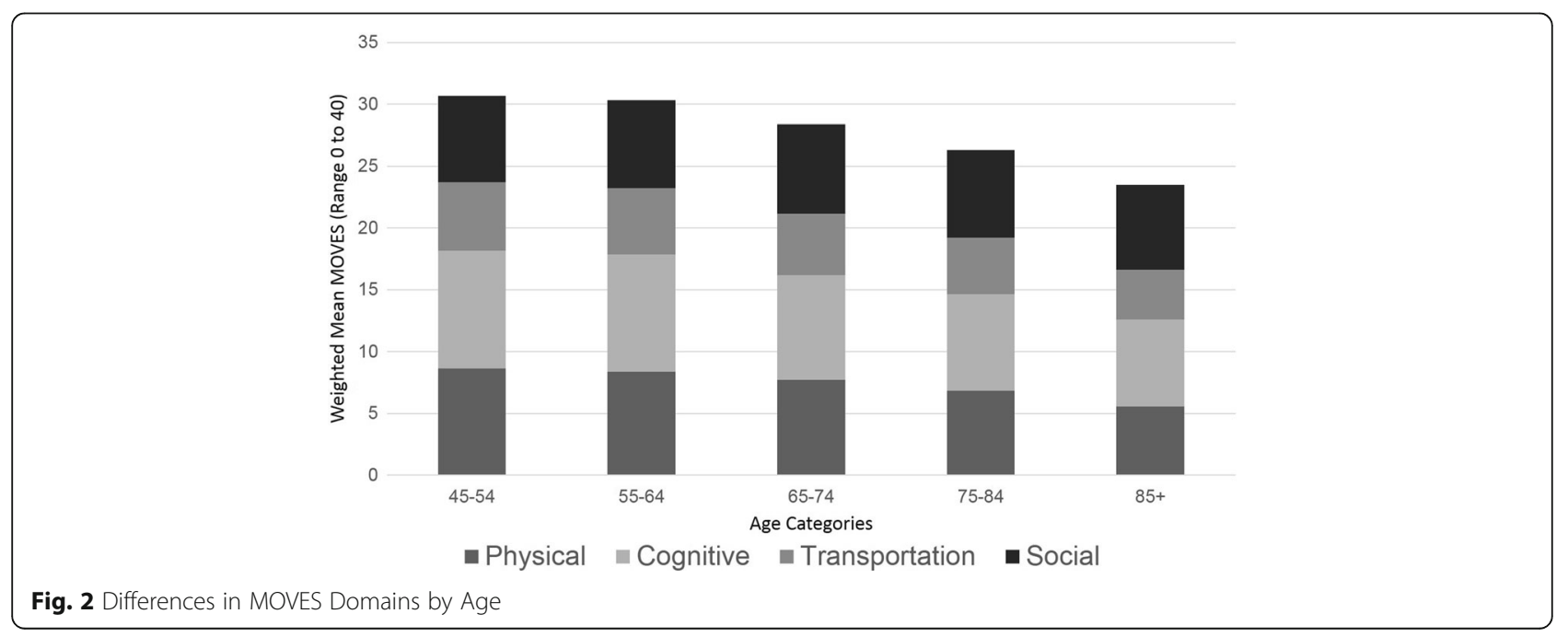




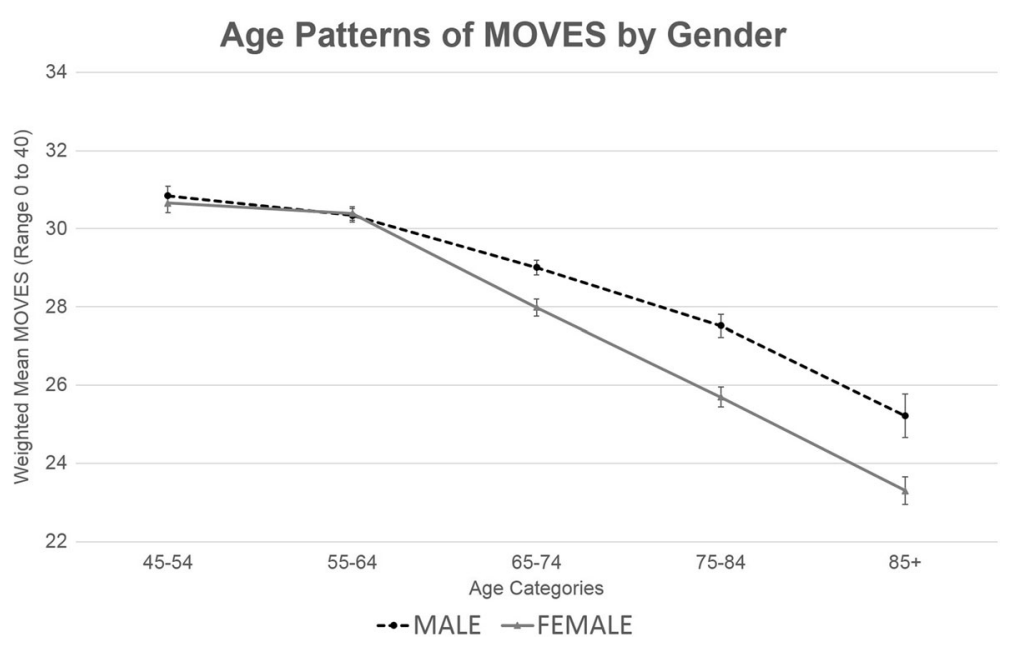

Fig. 3 Trend in MOVES with Age, by Gender

We acknowledge that MOVES has a number of limitations. MOVES was available for only those who answered all included items, assumed that those under 65 have no fear of falling, and items were restricted to those previously measured in CCHS-HA. Other practitioners may benefit from adding in questions on size of social network, cognitive ability to read and understand signage, or other measures related to the conceptual frameworks and domains. We also do not know how MOVES would perform for an institutionalized population. Our example using MOVES to examine mobility patterns also has limitations. First, a Canadian sample may not generalize to other populations. Second, our analyses are not analytic and therefore only show descriptive bivariate patterns between MOVES and the sociodemographic and health variables. Further work would be needed, including age- and other adjustments to examine associations causally. Finally, the sample used was a population-based sample of community dwelling middle-aged and older adults. It does not include people living in institutions, who may have lower mobility. We do not know how well the scale could be used to successfully differentiate between individuals or subgroups with very low levels of mobility. However, MOVES has numerous strengths across potential applications, and fills gaps created by limitations of other classification approaches. MOVES holds utility for researchers working in other population-based survey samples; since MOVES relies on common, pre-existing survey items, others with population surveys can derive a score to study holistic mobility. As such, this score is useful for benchmarking and tracking mobility across large geographic scales. Some MOVES items might not be common to other surveys. Future studies might test whether substituting similar items can be made without compromising the performance of MOVES. Similar to the descriptive analyses we provide, MOVES can be used to ascertain differences across gender, socioeconomic status, geographies and other characteristics. MOVES may also be used in natural experiments to examine changes in mobility with policy shifts or infrastructure investments, although we were unable to test how sensitive MOVES is to change using this cross-sectional sample. Similarly, researchers can use MOVES to understand the association between broad mobility and health outcomes, including self-rated health and overall mortality. Alternatively, MOVES could be used by policy makers and practitioners hoping to better understand mobility. MOVES provides insight on how well older adults are able to engage with their communities, and would enhance discussions around planning for driving cessation and maintaining mobility. Ultimately, MOVES represents the quantitative embodiment of evidence and conceptual frameworks of mobility. By assigning numeric values to these concepts, it further enhances discourse between various stakeholders around supports for older adult mobility and opens new avenues of research.

\section{Conclusion}

Grounded in frameworks and qualitative research that support conceptualizing mobility across physical, cognitive, transport and social domains, this study created a quantitative measurement tool (MOVES) for mobility that encompasses multiple domains. Descriptive data on MOVES in older adults from across Canada followed expected sociodemographic, economic, and health patterns of mobility levels. MOVES appears useful for research, surveillance, evaluation, and interventions around the broad factors influencing mobility in older adults. Future work could use MOVES to examine determinants, consequences and changes in of mobility for older adults across a range of setting and populations. 


\section{Additional files}

Additional file 1: Figure S1. Trend in MOVES with age, by Region (PNG $119 \mathrm{~kb}$ )

Additional file 2: Figure S2a. Trend in MOVES with age, by Region for Males (PNG $116 \mathrm{~kb}$ )

Additional file 3: Figure S2b. Trend in MOVES with age, by Region for Females (PNG $123 \mathrm{~kb}$ )

\section{Abbreviations}

ADL: Activities of Daily Living; ANOVA: Analysis of Variance; CCHSHA: Canadian Community Health Survey - Health Aging; Cl: 95\% Confidence Interval; CIHR: Canadian Institutes of Health Research; HUI: Health Utilities Index; IADL: Instrumental Activities of Daily Living; ICF: International Classification of Functioning, Disability and Health; MOS: Medical Outcomes Study; MOVES: Mobility Over Varied Environments Scale; NERI: New England Research Institutes; OARS: Older Americans Resources and Services; OMFAQ: OARS Multidimensional Functional Assessment Questionnaire@; PASE: Physical Activity Scale for the Elderly; PCA: Principal Component Analysis

\section{Acknowledgements}

Statistics Canada thanks all participants for their valuable input and advice during the development of the 2008/2009 Canadian Community Health Survey - Healthy Aging. Consultations included stakeholders from Human Resources and Social Development Canada and provincial and territorial health ministries. The authors would like to acknowledge the non-authors on the expert panel who assisted in development and refinement of MOVES Callista Haggis, Thea Franke, Christine Voss, Dawn Mackey, and Suzanne Therrien. This work was undertaken in the University of British Columbia and the Simon Fraser University Statistics Canada Research Data Centres with the assistance of Lee Grenon and Lisa Oliver.

\section{Funding}

The survey content was developed by the Health Statistics Division at Statistics Canada in consultation with Health Canada, the Public Health Agency of Canada, and experts conducting the Canadian Longitudinal Study on Aging (CLSA), a major strategic initiative of the Canadian Institutes of Health Research. The addition of 5000 respondents aged 45 to 54 was funded by the CLSA. Research was supported by the Canadian Institutes of Health Research (CIHR) grant number F14-03087. Hirsch is supported by the Population Research Training grant (T32 HD007168) and the Population Research Infrastructure Program (R24 HD050924) awarded to the Carolina Population Center at The University of North Carolina at Chapel Hill by the Eunice Kennedy Shriver National Institute of Child Health and Human Development. Sims-Gould is supported by a CIHR New Investigator award and a Michael Smith Foundation for Health Research Scholar award. Meghan Winters is supported by a Michael Smith Foundation for Health Research Scholar award. Ashe is supported by the Canada Research Chairs Program.

\section{Availability of data and materials}

The data that support the findings of this study are available from Statistics Canada but restrictions apply to the availability of these data, which were used within the Statistics Canada secure Research Data Centre (RDC) for the current study, and so are not publicly available. Data are, however, available for use within an RDC after appropriate clearance and approval by Statistics Canada.

\section{Authors' contributions}

$\mathrm{JH}$ and $\mathrm{HM}$ conceived of the idea to create a holistic measure of mobility. $\mathrm{JH}, \mathrm{MW}, \mathrm{JS}, \mathrm{PC}$, and MA designed the MOVES, tailored the MOVES after PCA and interpreted the results of the descriptive analysis. JH, MW, NS gained access to, analyzed, and guided the release of the CHHS-HA data. JH, MW, and $\mathrm{HM}$ contributed to writing the manuscript. All authors reviewed and approved the final manuscript.

\section{Competing interests}

The authors declare that they have no competing interests.

\section{Consent for publication}

Not applicable.

\section{Ethics approval and consent to participate}

This study did not require ethics review as it was deemed exempt under the Tri-Council Policy Statement: Ethical Conduct for Research Involving Humans

(TCPS 2), Article 2.4, by Simon Fraser University's Office of Research Ethics.

\section{Publisher's Note}

Springer Nature remains neutral with regard to jurisdictional claims in published maps and institutional affiliations.

\section{Author details}

${ }^{1}$ Department of Epidemiology and Biostatistics, Arnold School of Public Health, University of South Carolina, 915 Greene Street, Columbia, SC, USA. ${ }^{2}$ Centre for Hip Health and Mobility, Robert H.N. Ho Research Centre, University of British Columbia, 5th Floor, 2635 Laurel St, Vancouver, BC, Canada. ${ }^{3}$ Faculty of Health Sciences, Simon Fraser University, 8888 University Drive, Burnaby, BC, Canada. ${ }^{4}$ Department of Family Practice, University of British Columbia, 3rd Floor David Strangway Building, 5950 University Boulevard, Vancouver, BC, Canada. ${ }^{5}$ Department of Epidemiology, University of Michigan, 1415 Washington Heights, 4667 SPH I, Ann Arbor, MI, USA ${ }^{6}$ Institute for Social Research, University of Michigan, P.O. Box 1248426 Thompson St, Ann Arbor, MI, USA. ${ }^{7}$ Division of Orthopaedic Surgery, McGill University Health Centre, 1001 Boulevard Décarie, Montréal, QC, Canada. ${ }^{8}$ Department of Orthopaedics, University of British Columbia, 3114 - 910 West 10th Avenue, Vancouver, BC, Canada.

Received: 2 November 2016 Accepted: 17 May 2017

Published online: 25 May 2017

\section{References}

1. Kinsella KG, Wan H. Census USBot: An aging world: 2008. In: US Department of Commerce, Economics and Statistics Administration, US Census Bureau; 2009

2. Gardner P. The role of social engagement and identity in community mobility among older adults aging in place. Disabil Rehabil. 2014;36: 1249-57.

3. Marottoli RA, de Leon CFM, Glass TA, Williams CS, Cooney LM, Berkman LF. Consequences of driving cessation decreased out-of-home activity levels. J Gerontol Ser B Psychol Sci Soc Sci. 2000;55:S334-40.

4. Rosso AL, Taylor JA, Tabb LP, Michael YL. Mobility, disability, and social engagement in older adults. J Aging Health. 2013;25:617-37.

5. Boyle PA, Buchman AS, Barnes LL, James BD, Bennett DA. Association between life space and risk of mortality in advanced age. J Am Geriatr Soc. 2010;58:1925-30.

6. Cooper R, Kuh D, Hardy R. Objectively measured physical capability levels and mortality: systematic review and meta-analysis. BMJ. 2010;341:C4467.

7. Webber SC, Porter MM, Menec VH: Mobility in older adults: a comprehensive framework. Gerontologist. 2010. doi: 10.1093/geront/ gnq013.

8. International Classification of Functioning, Disability and Health (ICF). http:// www.who.int/classifications/icf/en/. Accessed 4 June 2016.

9. Mobility in Aging - a Strategic Initiative of the CIHR Institute of Aging http://www.cihr-irsc.gc.ca/e/29994.html. Accessed 4 June 2016.

10. Alsnih $\mathrm{R}$, Hensher DA. The mobility and accessibility expectations of seniors in an aging population. Transp Res A Policy Pract. 2003;37:903-16.

11. Metz D. Mobility of older people and their quality of life. Transp Policy. 2000;7:149-52.

12. Burns PC. Navigation and the mobility of older drivers. J Gerontol Ser B Psychol Sci Soc Sci. 1999;54:S49-55

13. Keysor JJ, Jette AM, LaValley MP, Lewis CE, Torner JC, Nevitt MC, et al. Community environmental factors are associated with disability in older adults with functional limitations: the MOST study. J Gerontol Ser A Biol Med Sci. 2010;65:393-9.

14. Clarke P, Ailshire JA, Bader M, Morenoff JD, House JS. Mobility disability and the urban built environment. Am J Epidemiol. 2008;168:506-13.

15. Clarke P, Ailshire JA, Lantz P. Urban built environments and trajectories of mobility disability: findings from a national sample of community-dwelling American adults (1986-2001). Soc Sci Med. 2009;69:964-70. 
16. Clarke P, Gallagher NA. Optimizing mobility in later life: The role of the urban built environment for older adults aging in place. J Urban Health. 2013:90:997-1009.

17. Clarke P, Nieuwenhuijsen ER. Environments for healthy ageing: A critical review. Maturitas. 2009;64:14-9.

18. Satariano WA, Ivey SL, Kurtovich E, Kealey M, Hubbard AE, Bayles CM, et al. Lower-body function, neighborhoods, and walking in an older population. Am J Prev Med. 2010;38:419-28.

19. Kerr J, Rosenberg D, Frank L. The role of the built environment in healthy aging community design, physical activity, and health among older adults. J Plan Lit. 2012;27:43-60.

20. Rosso AL, Auchincloss AH, Michael YL. The urban built environment and mobility in older adults: a comprehensive review. J Aging Res. 2011;2011

21. U.S. Environmental Protection Agency: Growing Smarter, Living Healthier: A guide to Smart Growth and Active Aging. Washington, DC: US Environmental Protection Agency; 2009

22. Farber N, Shinkle D, Lynott J, Fox-Grage W, Harrell R. Aging in Place: A State Survey of Livability Policies and Practices. Washington: AARP Public Policy Institute; 2011

23. Wolfson L, Whipple R, Amerman P, Tobin JN. Gait assessment in the elderly: a gait abnormality rating scale and its relation to falls. J Gerontol. 1990;45:M12-9.

24. Shumway-Cook A, Woollacott MH: Motor control: theory and practical applications. Philadelphia: Lippincott Williams \& Wilkins; 1995.

25. Podsiadlo D, Richardson S. The timed "Up \& Go": a test of basic functional mobility for frail elderly persons. J Am Geriatr Soc. 1991;39:142-8.

26. Lawton MP, Moss M, Fulcomer M, Kleban MH. A research and service oriented multilevel assessment instrument. J Gerontol. 1982;37:91-9.

27. Granger C, Gresham G. Functional assessment in rehabilitation medicine. Phys Med Rehabil Clin N Am. 1993;4:417-23.

28. Peel C, Baker PS, Roth DL, Brown CJ, Bodner EV, Allman RM. Assessing mobility in older adults: the UAB Study of Aging Life-Space Assessment. Phys Ther. 2005;85:1008-19.

29. Brown CJ, Bradberry C, Howze SG, Hickman L, Ray H, Peel C. Defining community ambulation from the perspective of the older adult. J Geriatr Phys Ther. 2010;33:56-63.

30. Statistics Canada: Canadian Community Health Survey - Healthy Aging (CCHS). Ottawa: Statistics Canada; 2010. http://www23.statcan.gc.ca/imdbbmdi/instrument/5146_Q1_V2-eng.pdf.

31. Fillenbaum GG, Smyer MA. The development, validity, and reliability of the OARS multidimensional functional assessment questionnaire. J Gerontol. 1981;36:428-34.

32. Feeny D, Furlong W, Torrance GW, Goldsmith CH, Zhu Z, DePauw S, et al. Multiattribute and single-attribute utility functions for the health utilities index mark 3 system. Med Care. 2002:40:113-28.

33. Dogra S, Stathokostas L: Sedentary behavior and physical activity are independent predictors of successful aging in middle-aged and older adults. J Aging Res. 2012;2012. http://dx.doi.org/10.1155/2012/190654.

34. Washburn RA, Smith KW, Jette AM, Janney CA. The Physical Activity Scale for the Elderly (PASE): development and evaluation. J Clin Epidemiol. 1993; 46:153-62.

35. Sherbourne CD, Stewart AL. The MOS social support survey. Soc Sci Med. 1991;32:705-14.

36. Edwards JD, Lunsman M, Perkins M, Rebok GW, Roth DL. Driving cessation and health trajectories in older adults. J Gerontol Ser A Biol Med Sci. 2009; 64:1290-5.

37. Uchino BN. Social support and health: a review of physiological processes potentially underlying links to disease outcomes. J Behav Med. 2006;29:377-87.

38. Berkman LF, Glass T, Brissette I, Seeman TE. From social integration to health: Durkheim in the new millennium. Soc Sci Med. 2000;51:843-57.

39. Dogra S, Stathokostas L. Correlates of extended sitting time in older adults: an exploratory cross-sectional analysis of the Canadian Community Health Survey Healthy Aging Cycle. Int J Public Health. 2014;59:983-91.

40. Lunney JR, Lynn J, Foley DJ, Lipson S, Guralnik JM. Patterns of functional decline at the end of life. JAMA. 2003;289:2387-92.

41. Kington RS, Smith JP. Socioeconomic status and racial and ethnic differences in functional status associated with chronic diseases. Am J Public Health. 1997:87:805-10.

42. Marengoni A, Angleman S, Melis R, Mangialasche F, Karp A, Garmen A, et al. Aging with multimorbidity: a systematic review of the literature. Ageing Res Rev. 2011;10:430-9.
43. Bassuk SS, Berkman LF, Amick BC. Socioeconomic status and mortality among the elderly: findings from four US communities. Am J Epidemiol. 2002;155:520-33.

44. Adler NE, Boyce T, Chesney MA, Cohen S, Folkman S, Kahn RL, et al. Socioeconomic status and health: the challenge of the gradient. Am Psychol. 1994;49:15.

45. Havens B, Hall M, Sylvestre $G$, Jivan T. Social isolation and loneliness: Differences between older rural and urban Manitobans. Can J Aging. 2004; 23:129-40.

46. Bacsu JR, Jeffery B, Johnson S, Martz D, Novik N, Abonyi S. Healthy aging in place: Supporting rural seniors' health needs. Online J Rural Nurs Health Care. 2012;12:77-87.

47. Xue Q-L, Fried LP, Glass TA, Laffan A, Chaves PH. Life-space constriction, development of frailty, and the competing risk of mortality the Women's health and aging study I. Am J Epidemiol. 2008;167:240-8.

\section{Submit your next manuscript to BioMed Central and we will help you at every step:}

- We accept pre-submission inquiries

- Our selector tool helps you to find the most relevant journal

- We provide round the clock customer support

- Convenient online submission

- Thorough peer review

- Inclusion in PubMed and all major indexing services

- Maximum visibility for your research

Submit your manuscript at www.biomedcentral.com/submit
) Biomed Central 